\title{
Research Paper: The Relationship Between Acoustic Characteristics and Personality Dimensions in Patients With Dysphonia
}

\author{
Somayeh Kasefy $^{1}$ (D) Farhad Torabinezhad $^{1^{*}}$ (D), Mahboobeh Rasouli ${ }^{2}$ (D), Bentolhoda Zareifaskhodi ${ }^{3}$ (D), Arezoo Saffarian ${ }^{1}$ (D) \\ 1. Department of Speech and Language Pathology, School of Rehabilitation Sciences, Iran University of Medical Sciences, Tehran, Iran. \\ 2. Department of Biostatistics, School of Public Health, Iran University of Medical Sciences, Tehran, Iran. \\ 3. Department of General Psychology, Karaj Branch, Islamic Azad University, Karaj, Iran.
}

\begin{tabular}{|l|l|l}
\hline $\begin{array}{c}\text { Use your device to scan } \\
\text { and read the article online }\end{array}$ & $\begin{array}{l}\text { Ceftation Kasefy S, Torabinezhad F, Rasouli M, Zareifaskhodi B, Saffarian A. The Relationship Between Acoustic Charac- } \\
\text { teristics and Personality Dimensions in Patients With Dysphonia. Iranian Rehabilitation Journal. 2020; 18(3):337-344. http:// } \\
\text { dx.doi.org/10.32598/irj.18.3.1046.1 }\end{array}$ \\
dol http://dx.doi.org/10.32598/irj.18.3.1046.1
\end{tabular}

Article info:

Received: 04 Jan 2020

Accepted: 18 May 2020

Available Online: 01 Sep 2020

Keywords:

Voice, Dysphonia, Personality, Acoustics

\section{A B S T RACT}

Objectives: Voice is influenced by personality. However, it is still questionable which acoustic features are influenced by personality traits. This study aimed to investigate the relationship between acoustic characteristics and personality dimensions.

Methods: Thirty-three participants with dysphonia and 33 participants without dysphonia were recruited to take part in this cross-sectional study. Personality dimensions were evaluated by the revised NEO personality inventory, and acoustic characteristics by using the Praat software. The tasks included prolongation of the vowel /a/, expression of declarative and interrogative sentences, reading, and connected speech. The acoustic features included fundamental frequency range, jitter, shimmer, harmonic-to-noise ratio, intensity, and duration. SPSS V. 23 was used for statistical analysis. For correlation analysis, the Pearson and Spearman correlation coefficients were employed.

Results: In individuals with dysphonia, a significant relationship was observed between personality dimensions and the following acoustic features: A. extraversion and intensity in connected speech $(\mathrm{P}=0.045)$ and the reading task $(\mathrm{P}=0.036)$; $\mathrm{B}$. openness and shimmer in $/ \mathrm{a}$ vowel prolongation $(\mathrm{P}=0.003)$; $\mathrm{C}$. openness and the harmonic-to-noise ratio in $/ \mathrm{a} /$ the vowel prolongation task $(\mathrm{P}=0.017)$; and $\mathrm{D}$. agreeableness and duration in expressing interrogative sentences $(\mathrm{P}=0.019)$.

Discussion: In Persian-speaking participants with and without dysphonia, some acoustic characteristics were significantly correlated with the mean score of the personality test (revised NEO personality inventory). It seems that each voice feature is influenced by personality dimensions. This finding indicates that changes in acoustic characteristics of voice due to personality can be evaluated in laboratory and hearing examinations.

\section{* Corresponding Author:}

Farhad Torabinezhad, PhD.

Address: Department of Speech and Language Pathology, School of Rehabilitation Sciences, Iran University of Medical Sciences, Tehran, Iran. Tel: +98 (912) 7632809

E-mail: torabinezhad.f@iums.ac.ir 


\section{Highlights}

- In people with dysphonia, intensity, shimmer, harmonics to noise, and duration are associated with personality.

- In people with dysphonia, personality dimensions, including extraversion, openness, and agreeableness are associated with acoustic characteristics.

- Some of these relationships might be a sign of increased vocal misuse based on the personality dimensions of individuals.

\section{Plain Language Summary}

There are several causes of dysphonia. One of the most important causes that speech therapists tend to overlook is personality. According to numerous studies, personality plays a key role in the prevention and treatment of dysphonia. In this study, we investigated the relationship between the acoustic characteristics of voice and personality dimensions in patients with dysphonia. The results of our study showed that intensity was significantly correlated with extraversion; shimmer, and harmonic to noise with openness; and duration with agreeableness.

\section{Introduction}

ysphonia (voice disorder) occurs in

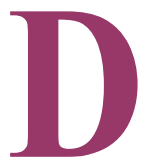
both children and adults, but its causes differ at different ages [1]. As for the etiology of voice disorder, several causes are blamed such as respiratory system disorders, asthma and allergies, vocal abuse and misuse, smoking, reflux, and psychological and emotional problems $[1,2]$. Vocal misuse and the pattern of voice production, which are related to emotional and personality factors [2-4] are among the most significant factors in the development of voice disorder [2]. In this regard, one of the causes of voice misuse and abuse is the personality of individuals [2, 3].

Personality is described as a set of consistent behavioral characteristics that result in behavioral differences among people in response to the same situation and the differentiation of individuals [5]. Based on the 5-factor model, most aspects of personality come from 5 major attributes: neuroticism, extraversion, openness, agreeableness, and conscientiousness $[5,6]$. These 5 -factor personality traits define the modes of thinking, feeling, as well as behavior of individuals based on their personality [7].

Based on the personality trait theory of voice disorders, personality traits, including extraversion and neuroticism can predispose individuals to voice disorders and play a significant role in survival as well as the reversal of voice disorder following treatment $[2,8]$. People with certain personality traits may have vocal behaviors that lead to phonotrauma, which ultimately results in laryngeal le- sions such as nodules and polyps [3, 8, 9]. For example, extraverts tend to have verbal communication and make excessive use of voice, which causes phonotrauma $[2,10]$.

Stress is a major risk factor for voice disorder [1]. Stress and anxiety stimulate laryngeal motor inhibition [11], increase or decrease laryngeal muscle activity [12-14], and lead to improper use of laryngeal muscles [2]. These changes in the larynx as a result of stress and anxiety result in complaints such as pain, fatigue, and vocal effort in people suffering from muscle tension dysphonia (MTD) $[11,12]$ and even in those with a high level of anxiety without any dysphonia [15]. Acoustic parameters of the voice reflect the physiology of vocal folds [13] and change under the influence of personality traits and stress [16]. Various studies have investigated the personality trait theory and the effect of stress and emotions on voice $[13,14,17,18]$. This theory confirms the role of personality traits in changing laryngeal functions [2, 14]. The different patterns of voice production, based on personality traits, result in changes in the biomechanics of vocal folds as well as the person susceptible to voice disorder [9, 12]

As previously discussed, several studies have been conducted on the effect of stress on the larynx and voice disorders $[3,4,10,19]$; however, fewer studies have investigated the relationship between acoustic characteristics and personality traits $[10,20,21]$. Since personality traits are regarded as a significant risk factor for the prevention and treatment of voice disorder $[2,8]$, the present study was designed to assess the hypothesis that personality dimensions alter the acoustic characteristics of voice, and these changes can be traced in speech as well 
as acoustic characteristics. Specifically, this study aimed to investigate the relationship between acoustic characteristics and personality dimensions in Persian-speaking individuals with and without dysphonia.

\section{Methods}

\section{Study participants}

The sample size was calculated based on a fundamental frequency according to prior research [22]. The participants with dysphonia were matched with those without dysphonia in terms of age and sex. The number of participants was 66, and the sample size was 33 in each group (17 men and 16 women). Their Mean \pm SD age was $39.67 \pm 10.911$ years in the group with dysphonia and $38.42 \pm 8.426$ years in the group without dysphonia. The convenience sampling was performed in the otorhinolaryngology division of Hazrat-Rasoul Hospital as well as the speech therapy clinic, school of rehabilitation sciences, Iran University of Medical Sciences (Tehran, Iran). The participants completed demographic information sheets and consent forms. The inclusion criterion for the dysphonic participants was the detection and identification of dysphonia by a laryngologist. The inclusion criterion for the non-dysphonic participants was perceptual evaluation according to the GRBAS (grade, roughness, breathiness, asthenia, strain) scale by three speech therapists, no history of hoarseness or laryngeal disease in recent months, adequate writing and reading literacy, being Persian-speaking, and no history of mental illness such as depression. The last three criteria were common in both groups with and without dysphonia. The exclusion criteria were the subjects' unwillingness to participate, noise in the recorded voice samples, or incomplete information of the questionnaires. Gender segregation and the type of dysphonia were not taken into account because of the small sample size.

\section{Assessment of personality dimensions}

The participants were asked to complete the NEO personality inventory (short form), which is one of the most reliable tests of personality psychology with good validity and reliability [6]. This questionnaire examines 5 important personality dimensions: extraversion, neuroticism, openness, agreeableness, and conscientiousness. The NEO personality inventory contains 60 items, with each dimension comprising 12 items. The individuals respond to each item on a 5-point Likert scale, including "Totally agree", "Agree", "Disagree", "Totally disagree", and "No opinion". Then, the individual's score is determined for each attribute. A high score in each attri- bute indicates that the personality dimension is relatively more dominant $[5,6]$.

\section{Evaluation of acoustic parameters}

The fundamental frequency range (F0 range), duration, intensity, jitter, shimmer, and harmonic-to-noise (HNR) ratio were investigated. The recorder used to record voices (Model: ZOOM H5, Japan) was positioned at a 45-degree angle and $10 \mathrm{~cm}$ away from the participant's mouth. The recording was performed in a quiet environment and at the same time for all participants. The tasks included sustaining vowel /a/ for 5 seconds, expressing declarative and interrogative sentences/ dare barun miyad./ and /chi meyl darin?/ [23], reading a valid and reliable text [24], and the connected speech task. To eliminate the effect of the glottal attack on the vowel start, the initial 0.5 seconds were removed in the vowel prolongation task. Acoustic features were measured in all tasks. However, to express the results, only factors with a significant correlation were mentioned. The samples were analyzed using the Praat software (version 5,4,08).

Statistical analysis was performed in SPSS V. 23. The Shapiro-Wilk test was used to check the normality of the data. Accordingly, the independent t test and MannWhitney $U$ test were used to compare the groups with and without dysphonia. Besides, the Pearson/Spearman correlation coefficient was employed to investigate the relationship between acoustic characteristics and personality dimensions. The significance level (P-value) was considered $<0.05$.

\section{Results}

The Pearson/Spearman correlation coefficient was used to examine the relationship between acoustic features and personality dimensions. In patients with dysphonia, extraversion had a significant and positive relationship with the mean value of intensity in connected speech $(\mathrm{r}=0.351, \mathrm{P}=0.045)$ and text reading $(\mathrm{r}=0.366, \mathrm{P}=0.036)$. Also, openness had a significant and negative correlation with shimmer in the prolongation of the vowel /a/ $(\mathrm{r}=-0.500, \mathrm{P}=0.003)$ and a significant and positive relationship with HNR in the prolongation of the vowel /a/ $(\mathrm{r}=0.411, \mathrm{P}=0.017)$. There was a significant and negative correlation between agreeableness in the group with dysphonia with duration in expressing interrogative sentences ( $\mathrm{r}=-0.406, \mathrm{P}=0.019)$ (Table 1$)$.

The findings revealed that in individuals without dysphonia, there is a significant and positive relationship 
Table 1. Results of the correlation between voice features and personality dimensions in participants with dysphonia

\begin{tabular}{|c|c|c|c|c|c|c|c|c|c|c|}
\hline \multirow[b]{2}{*}{$\begin{array}{l}\text { Voice Vari- } \\
\text { able }\end{array}$} & \multicolumn{2}{|c|}{ Neuroticism } & \multicolumn{2}{|c|}{ Extraversion } & \multicolumn{2}{|c|}{ Openness } & \multicolumn{2}{|c|}{ Agreeableness } & \multicolumn{2}{|c|}{ Conscientiousness } \\
\hline & $\begin{array}{c}\text { Correlation } \\
\text { Coeffi- } \\
\text { cients }\end{array}$ & $\mathbf{P}$ & $\begin{array}{l}\text { Correlation } \\
\text { Coefficients }\end{array}$ & $\mathbf{P}$ & $\begin{array}{l}\text { Correlation } \\
\text { Coefficients }\end{array}$ & $\mathbf{P}$ & $\begin{array}{c}\text { Correlation } \\
\text { Coeffi- } \\
\text { cients }\end{array}$ & $\mathbf{P}$ & $\begin{array}{c}\text { Correlation } \\
\text { Coeffi- } \\
\text { cients }\end{array}$ & $\mathbf{P}$ \\
\hline Jitter (\%) & -0.318 & 0.072 & 0.039 & 0.828 & -0.156 & 0.387 & 0.281 & 0.113 & 0.168 & 0.351 \\
\hline $\begin{array}{c}\text { Shimmer } \\
(\%)\end{array}$ & -0.181 & 0.313 & -0.013 & 0.945 & $-0.500 * \downarrow$ & 0.003 & 0.100 & 0.578 & 0.240 & 0.178 \\
\hline $\begin{array}{l}\text { Harmonic- } \\
\text { to-noise } \\
\text { ratio }(\mathrm{dB})\end{array}$ & 0.320 & 0.069 & -0.137 & 0.446 & $0.411 * \uparrow$ & 0.017 & -0.196 & 0.273 & 0.025 & 0.890 \\
\hline $\begin{array}{l}\text { F0 range in } \\
\text { declarative } \\
\text { sentences } \\
(\mathrm{Hz})\end{array}$ & 0.005 & 0.980 & -0.171 & 0.341 & 0.179 & 0.320 & 0.190 & 0.291 & 0.315 & 0.074 \\
\hline $\begin{array}{l}\text { Voice dura- } \\
\text { tion when } \\
\text { expressing } \\
\text { interroga- } \\
\text { tive sen- } \\
\text { tences (S) }\end{array}$ & 0.275 & 0.122 & -0.108 & 0.548 & -0.191 & 0.287 & $-0.406 * \downarrow$ & 0.019 & -0.337 & 0.055 \\
\hline $\begin{array}{c}\text { Voice } \\
\text { intensity in } \\
\text { connected } \\
\text { speech (dB) }\end{array}$ & -0.222 & 0.213 & $0.351 * \uparrow$ & 0.045 & -0.173 & 0.337 & 0.186 & 0.299 & 0.290 & 0.102 \\
\hline $\begin{array}{l}\text { Voice } \\
\text { intensity in } \\
\text { text reading } \\
\text { (dB) }\end{array}$ & 0.026 & 0.887 & $0.366 * \uparrow$ & 0.036 & -0.104 & 0.566 & 0.148 & 0.410 & 0.340 & 0.053 \\
\hline
\end{tabular}

Пranian Rehabilitation Journal

Significant level is identified with *, and an increase or decrease of the acoustic characteristic is identified with $\uparrow \downarrow$.

between agreeableness and the $\mathrm{F} 0$ range in expressing declarative sentences $(\mathrm{r}=0.472, \mathrm{P}=0.006)$ (Table 2$)$.

Personality test scores were calculated, and no significant difference was observed between individuals with and without dysphonia in any of the personality dimen- sions $(\mathrm{P}>0.05)$ (Figure 1). Besides, the acoustic analysis between the subjects with and without dysphonia showed only a significant difference in $\operatorname{HNR}(\mathrm{P}=0.015)$ (Table 3).

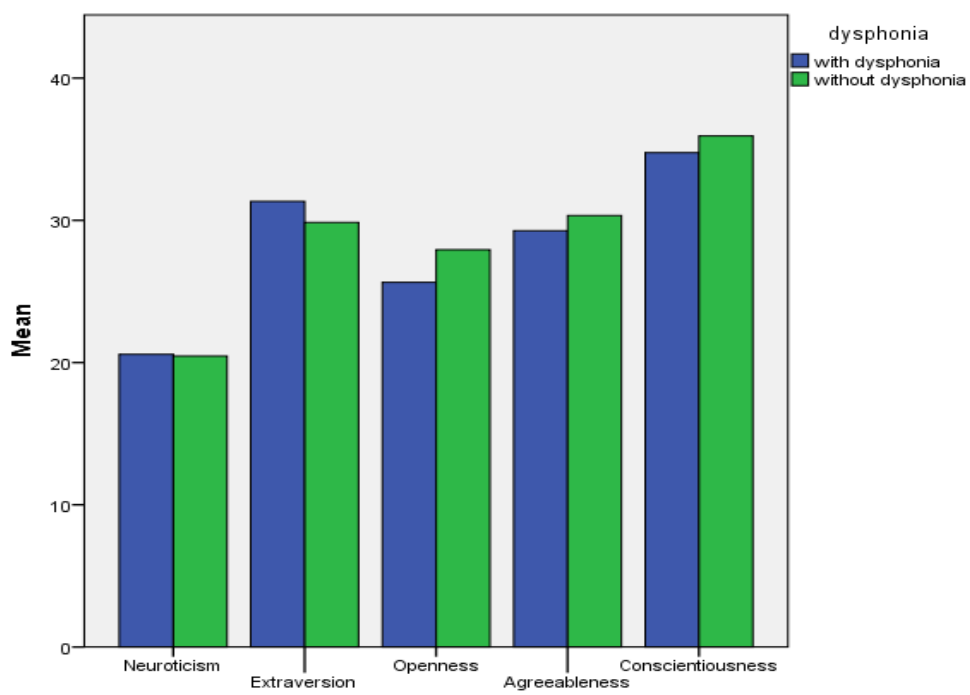

Figure 1. Personality dimension scores in participants with and without dysphonia 
Table 2. Results of the correlation between voice features and personality dimensions in participants without dysphonia

\begin{tabular}{|c|c|c|c|c|c|c|c|c|c|c|}
\hline \multirow[b]{2}{*}{$\begin{array}{l}\text { Voice Vari- } \\
\text { able }\end{array}$} & \multicolumn{2}{|c|}{ Neuroticism } & \multicolumn{2}{|c|}{ Extraversion } & \multicolumn{2}{|c|}{ Openness } & \multicolumn{2}{|c|}{ Agreeableness } & \multicolumn{2}{|c|}{ Conscientiousness } \\
\hline & $\begin{array}{l}\text { Correlation } \\
\text { Coefficients }\end{array}$ & $\mathbf{P}$ & $\begin{array}{l}\text { Correlation } \\
\text { Coefficients }\end{array}$ & $\mathbf{P}$ & $\begin{array}{l}\text { Correlation } \\
\text { Coefficients }\end{array}$ & $\mathbf{P}$ & $\begin{array}{l}\text { Correlation } \\
\text { Coefficients }\end{array}$ & $\mathbf{P}$ & $\begin{array}{c}\text { Correlation } \\
\text { Coeffi- } \\
\text { cients }\end{array}$ & $\mathbf{P}$ \\
\hline Jitter (\%) & -0.239 & 0.181 & 0.068 & 0.706 & 0.118 & 0.513 & -0.092 & 0.612 & 0.008 & 0.965 \\
\hline $\begin{array}{c}\text { Shimmer } \\
(\%)\end{array}$ & -0.259 & 0.145 & 0.305 & 0.085 & 0.281 & 0.113 & -0.086 & 0.635 & -0.070 & 0.697 \\
\hline $\begin{array}{l}\text { Harmonic- } \\
\text { to-noise } \\
\text { ratio }(\mathrm{dB})\end{array}$ & 0.252 & 0.157 & -0.111 & 0.539 & -0.095 & 0.600 & 0.117 & 0.516 & 0.113 & 0.530 \\
\hline $\begin{array}{c}\text { F0 range in } \\
\text { declarative } \\
\text { sentences } \\
(\mathrm{Hz})\end{array}$ & -0.294 & 0.097 & 0.243 & 0.173 & 0.150 & 0.406 & 0.472 & 0.006 & 0.274 & 0.122 \\
\hline $\begin{array}{l}\text { Voice dura- } \\
\text { tion when } \\
\text { expressing } \\
\text { interroga- } \\
\text { tive sen- } \\
\text { tences (S) }\end{array}$ & -0.083 & 0.644 & 0.046 & 0.800 & 0.115 & 0.523 & -0.088 & 0.626 & -0.122 & 0.500 \\
\hline $\begin{array}{c}\text { Voice } \\
\text { intensity in } \\
\text { connected } \\
\text { speech (dB) }\end{array}$ & -0.136 & 0.450 & 0.328 & 0.062 & -0.019 & 0.916 & 0.096 & 0.593 & 0.067 & 0.711 \\
\hline $\begin{array}{l}\text { Voice } \\
\text { intensity in } \\
\text { text reading } \\
\text { (dB) }\end{array}$ & 0.012 & 0.949 & 0.034 & 0.849 & -0.019 & 0.916 & -0.097 & 0.593 & -0.104 & 0.564 \\
\hline
\end{tabular}

Iranian R̃ehabilitation \ournal

Description: Significant level is identified with*, and an increase or decrease of the acoustic characteristic is identified with $\uparrow \downarrow$.

Table 3. Acoustic analysis results of participants with and without dysphonia

\begin{tabular}{|c|c|c|c|c|}
\hline \multirow{2}{*}{ Acoustic Parameters } & \multirow{2}{*}{ Task } & \multicolumn{2}{|c|}{ Mean $\pm S D$} & \multirow{2}{*}{$\mathbf{P}$} \\
\hline & & With Dysphonia & Without Dysphonia & \\
\hline Jitter (\%) & Prolongation of the vowel/a/ & $0.708 \pm 1.436$ & $0.360 \pm 0.144$ & 0.160 \\
\hline Shimmer (\%) & Prolongation of the vowel/a/ & $3.486 \pm 3.015$ & $2.365 \pm 0.798$ & 0.121 \\
\hline HNR (dB) & Prolongation of the vowel/a/ & $23.329 \pm 5.077$ & $26.000 \pm 3.488$ & $0.015^{*}$ \\
\hline FO range $(\mathrm{HZ})$ & Expressing declarative sentence & $110.294 \pm 81.808$ & $123.126 \pm 89.246$ & 0.517 \\
\hline Voice duration (S) & Expressing interrogative sentence & $0.970 \pm 0.144$ & $0.926 \pm 0.132$ & 0.208 \\
\hline Voice intensity (dB) & Connected speech & $56.30 \pm 2.791$ & $55.60 \pm 2.699$ & 0.301 \\
\hline Voice intensity (dB) & Text reading & $57.78 \pm 2.726$ & $56.90 \pm 1.765$ & 0.121 \\
\hline
\end{tabular}

\section{Discussion}

Based on the findings, some acoustic features have a significant relationship with personality dimensions. Larynx is an organ that is sensitive to emotions and personality $[3,12,13]$, and voice quality is affected by emotions and personality traits $[16,21]$.
The results of this study may confirm the personality trait theory of voice disorders and the role of personality traits in changing the physiology of voice [2]. Also, the findings of the present study are consistent with those of the studies expressing that different vocal performances occur in various emotional states $[13,16]$. The findings of this study showed that various personality dimensions, namely emotions alter the acoustic parameters of voice. 
According to the findings, in people with dysphonia, extraversion has a significant positive relationship with intensity (in the tasks of reading and connected speech). Other studies also report changes in laryngeal muscle activity and voice intensity as a result of extraversion [11, 18]. Poulain et al. also concluded that voice intensity in children has a positive relationship with extraversion personality [21]. In the study by Mattei et al., extroverts had more intensity than introverts (especially in difficult communication situations) [10]. It seems that the self-confidence of extroverts can be reflected in their voice [21] because they are energetic and dynamic people and feel comfortable in developing relationships with others $[5,7]$. Besides, more extroverted children speak louder [21]. Also, in this study, extroverts who showed more emotions and spoke louder. In other words, the high energy of extroverts is obvious in their voice intensity. On the other hand, increasing voice intensity as well as voice loudness can increase vocal effort [10], and this may increase phonotrauma [2] and the risk of dysphonia in these individuals.

In patients with dysphonia, openness had a significantly negative relationship with shimmer. Studies showed that emotions and stress influence perturbation (including shimmer) $[16,25]$. Perturbation is due to hypo/hypertension of glottal adduction, and as distress increases, the rate of vocal fold vibration also rises [16]. Openness is regarded as a personality dimension directly related to creativity and intelligence and can contribute to increasing one's stress tolerance [5]. Openness people are less focused on memories, thoughts, emotions, and body feelings, so this trait is likely to result in reduced levels of anxiety and stress. These individuals enjoy deeper experiences as well as distinct and differentiated emotional states [5], which probably result in less confusion with various emotions, experiencing less tension, and accepting their excitements. Experiencing less stress and despairing confrontation with unpleasant excitements such as anxiety and disappointment will probably affect the tension and physiology of the laryngeal muscles, including shimmer. However, the results of a study demonstrated no significant difference in shimmer in stress and relaxed conditions [9]. The different results of this study may be due to the types of tasks, materials, and research methods.

In the present study, there was a significant and positive relationship between openness and HNR in people with dysphonia. HNR is important in differentiating emotions [16]. It seems that openness is prone to change emotions due to the experience of new positive and negative emotions [5] and thus changes in the HNR. As we know, HNR shows the amount of extra noise in voice signals and is regarded as a good indicator of hoarseness as well as roughness [26]. An increase in this acoustic feature is a sign of noise reduction in the voice signal [26]. The findings of this study revealed that with an increase in the level of openness, the amount of HNR is equally increased. This means that by increasing these personality dimensions, less hoarseness is likely to be heard in a person's voice.

Agreeableness is also significantly and negatively related to duration (in expressing interrogative sentences) in participants with dysphonia. Due to altruism, individuals with more agreeableness are more comfortable in social relationships and less likely to have impulses [5, 20], and this probably causes them to speak with fewer pauses. The results of the present study indicate that people with more agreeableness are less likely to doubt when questioning, and therefore, ask the question faster and in a shorter duration.

On the other hand, this study showed that only agreeableness had a significant and positive relationship with the F0 range (in the task of expressing declarative sentences) in individuals without dysphonia. The fundamental frequency change is related to the activity of the autonomic nervous system and provides information about the emotional state of the speaker [13]. Therefore, an increase in the F0 range when expressing declarative sentences can probably be a sign of good verbal communication and better expression of emotion in a person with more agreeableness.

In this study, neuroticism and conscientiousness in individuals with and without dysphonia had no significant relationship with any of the acoustic features. This result is not consistent with the personality trait theory of voice disorders (Roy's study) [2, 8]. According to this theory, neuroticism is considered as of the key and effective factors on voice, especially in disorders such as nodules and functional voice disorders $[2,8]$. This disagreement may be due to the different sample sizes, types of materials, and methods of the two studies $[2,8]$. The psychological tests used in Roy's study were different from those employed in the present study. In Roy's study, the multidimensional personality questionnaire and Eysenck personality questionnaire were utilized to compare the personality traits $[2,8]$. Here, however, the NEO personality inventory was employed to examine the personality dimensions. On the other hand, Roy's research does not address any of the acoustic parameters of voice and only emphasizes the role of neuroticism characteristics in causing dysphonia.

Thus, the personality profile of the speaker can be an explanation for his or her speech production model [20]. 
According to the findings of this study, personality dimensions may also influence voice, so it is recommended that these dimensions be considered in treatment. Emotional and personality traits should be taken into account for better treatment outcomes both in disorders caused by organ changes in the larynx and functional voice disorders $[3,11]$.

In addition, the further activity of the external laryngeal muscle due to the personality of individuals affects the position of the larynx and, consequently, influences the condition of internal muscles and their function [12, 14]. In such a situation, if the personality traits of people suffering from dysphonia are considered and adjusted, it can be expected that the position of the external muscles of the larynx and, consequently, the larynx be changed in a better way and the treatment process proceed better and at a faster rate. Therefore, in selecting the treatment procedure for patients with dysphonia, therapeutic techniques should be selected to maintain a balance between voice therapy and personality traits $[2,3,11]$.

The limitations of the present research include the small sample size and lack of distribution between groups due to age, sex, and type of dysphonia. It is suggested that future studies measure other acoustic characteristics under stressful conditions, recruit a larger sample, and take into account age, sex, and various types of dysphonia.

\section{Conclusion}

The results of this study suggest that acoustic characteristics are affected by personality dimensions, including extraversion, openness, and agreeableness, and there are relationships between them. These relationships are significant in people with and without dysphonia and can be evaluated through hearing as well as laboratory tests. Therefore, it is suggested that speech and language pathologists focus on these relationships for the prevention and treatment of dysphonia.

\section{Ethical Considerations}

\section{Compliance with ethical guidelines}

Ethics and Research Committee of Iran University of Medical Sciences approved the present study (Code: IR.IUMS.REC.1397.094).

\section{Funding}

This project was supported and funded by the Rehabilitation Research Center, School of Rehabilitation Sci- ences of Iran University of Medical Sciences (Grant No. 98-3-31-15745).

\section{Authors' contributions}

All authors equally contributed to designing, running, and writing all parts of the research.

\section{Conflict of interest}

The authors have no conflicts of interest to declare.

\section{References}

[1] Vertanen-Greis H, Löyttyniemi E, Uitti J. Voice disorders are associated with stress among teachers: A cross-sectional study in finland. Journal of Voice. 2020; 34(3):488.e1-8. [DOI: 10.1016/j.jvoice.2018.08.021] [PMID]

[2] Roy N, Bless DM, Heisey D. Personality and voice disorders: A multitrait-multidisorder analysis. Journal of Voice. 2000; 14(4):521-48. [DOI:10.1016/S0892-1997(00)80009-0] [PMID]

[3] Abeida MEU, Liesa RF, Varela HV, Campayo JG, Gormedino PR, García AO. Study of the influence of psychological factors in the etiology of vocal nodules in women. Journal of Voice 2013; 27(1):129.e15-20. [DOI:10.1016/j.jvoice.2011.08.012] [PMID]

[4] Deary V, Miller T. Reconsidering the role of psychosocial factors in functional dysphonia. current opinion in otolaryngology \& head and neck surgery. 2011; 19(3):150-4. [DOI:10.1097/ MOO.0b013e328346494d] [PMID]

[5] Wright JD. International encyclopedia of the social \& behavioral sciences. $2^{\text {th }}$ ed. Amsterdam: Elsevier Science; 2015.

[6] Garoosi M. [NEO Personality Test and standarization of new methods structure and factor among students in Iranian universities (Persian)]. Tehran: Tarbiat Modarres University; 1990

[7] South SC, Jarnecke AM, Vize CE. Sex differences in the Big Five model personality traits: A behavior genetics exploration. Journal of Research in Personality. 2018; 74:158-65. [DOI:10.1016/j.jrp.2018.03.002]

[8] Roy N, Bless DM. Personality traits and psychological factors in voice pathology: A foundation for future research. Journal of Speech, Language, and Hearing Research. 2000; 43(3):737-48. [DOI:10.1044/jslhr.4303.737] [PMID]

[9] Van Lierde K, Van Heule S, De Ley S, Mertens E, Claeys S. Effect of psychological stress on female vocal quality. Folia Phoniatrica et Logopaedica. 2009; 61(2):105-11. [DOI:10.1159/000209273] [PMID]

[10] Mattei A, Legou T, Cardeau A, Le Goff J, Lagier A, Giovanni A. Acoustic correlates of vocal effort: External factors and personality traits. European Annals of Otorhinolaryngology, 
Head and Neck Diseases. 2019 ;136(3):151-4. [DOI:10.1016/j. anorl.2019.02.010] [PMID]

[11] Dietrich M, Abbott KV. Psychobiological stress reactivity and personality in persons with high and low stressor-induced extralaryngeal reactivity. Journal of Speech, Language, and Hearing Research. 2014; 57(6):2076-89. [DOI:10.1044/2014_JSLHR-S-12-0386] [PMID]

[12] Dietrich M, Abbott KV. Vocal function in introverts and extraverts during a psychological stress reactivity protocol. Journal of Speech, Language, and Hearing Research. 2012; 55(3):973-87. [DOI:10.1044/1092-4388(2011/10-0344)] [PMID]

[13] Perrine BL. [The Influence of stress on the voice (English)]. [PhD. thesis]. Bowling Green: Bowling Green State University; 2018.

[14] Roy N, Dietrich M, Blomgren M, Heller A, Houtz DR, Lee J. Exploring the neural bases of primary muscle tension dysphonia: A case study using functional magnetic resonance imaging. Journal of Voice. 2019; 33(2):183-94. [DOI:10.1016/j. jvoice.2017.11.009] [PMID]

[15] Gomes VEFI, da Costa Batista D, Lopes LW, Aquino R, Almeida AA. Symptoms and vocal risk factors in individuals with high and low anxiety. Folia Phoniatrica et Logopaedica. 2019; 71(1):7-15. [DOI:10.1159/000494211] [PMID]

[16] Patel S, Scherer KR, Björkner E, Sundberg J. Mapping emotions into acoustic space: The role of voice production Biological psychology. 2011; 87(1):93-8. [DOI:10.1016/j.biopsycho.2011.02.010] [PMID]

[17] Hashim NW, Wilkes M, Salomon R, Meggs J, France DJ. Evaluation of voice acoustics as predictors of clinical depression scores. Journal of Voice. 2017; 31(2):256.e1-6. [DOI:10.1016/j. jvoice.2016.06.006] [PMID]

[18] van Mersbergen M, Delany M. Vocal responses to emotional picture viewing. Logopedics Phoniatrics Vocology. 2014; 39(3):99-107. [DOI:10.3109/14015439.2013.777108] [PMID]

[19] Almeida AAFd, Fernandes LR, Azevedo EHM, Pinheiro RSdA, Lopes LW, editors. Characteristics of voice and personality of patients with vocal fold immobility. CoDAS, 2015 ; 27(2):178-85. [DOI:10.1590/2317-1782/20152014144] [PMID]

[20] Guidi A, Gentili C, Scilingo EP, Vanello N. Analysis of speech features and personality traits. Biomedical Signal Processing and Control. 2019; 51:1-7. [DOI:10.1016/j.bspc.2019.01.027]

[21] Poulain T, Fuchs M, Vogel M, Jurkutat A, Hiemisch A, Kiess $\mathrm{W}$, et al. Associations of speaking-voice parameters with personality and behavior in school-aged children. Journal of Voice 2020; 34(3):485.e23-31. [DOI: 10.1016/j.jvoice.2018.09.022] [PMID]

[22] Ghorbani A, Saffarian A, Torabinezhad F, Amiri Shavaki Y, Keyhani MR. [The profile of fundamental frequency changes in normal Persian-speaking individuals 9-50 years old (Persian)]. Audiol. 2010; 19(2):57-64. https://aud.tums.ac.ir/article-1-97-en.html

[23] Nickravesh M, Torabinezhad F, Ghorbani A, Keyhani M. [Intonation and duration curve in Persian interrogative sentences (Persian)]. Audiology. 2012; 21(1):54-61. https://aud. tums.ac.ir/article-1-55-en.html
[24] Torabinezhad F. [Design Persian passage for measurement of acoustic parameters in voice disorders (persian)]. [PhD. thesis]. Tehran: Iran University of Medical Sciences.

[25] MacPherson MK, Abur D, Stepp CE. Acoustic measures of voice and physiologic measures of autonomic arousal during speech as a function of cognitive load. Journal of Voice. 2017; 31(4):e1-9. [DOI:10.1016/j.jvoice.2016.10.021] [PMID] [PMCID]

[26] Ferrand CT. Harmonics-to-noise ratio: An index of vocal aging. Journal of Voice. 2002; 16(4):480-7. [DOI:10.1016/ S0892-1997(02)00123-6] 